\title{
Doença de Ménétrier: relato de caso em menina
}

\author{
Ménétrier's disease: a female child case report
}

Lidiana Morais Longo ${ }^{1}$, Bárbara Zilioli C. Santos², Caroline Fidelis R. Souza ${ }^{3}$, Francisco Gozi ${ }^{3}$, Emílio Luis Dorda Antônio Augusto C. Santos ${ }^{4}$

\section{RESUMO}

Objetivo: Relatar um caso de menina com doença de Ménétrier.

Descrição do caso: Menina de dez anos, admitida com história de vômitos, diarréia, distensão e dor abdominal intermitentes há três dias. A suspeita foi apendicite e a paciente foi submetida à laparotomia, com achado de ascite e adenomegalia mesentérica. No pós-operatório, evoluiu com edema generalizado, ascite e derrame pleural. Os exames complementares e a evolução clínica demonstraram tratar-se de doença de Ménétrier.

Comentários: $\mathrm{O}$ quadro clínico e os exames solicitados (alfa-1-antitripsina fecal aumentada, mucosa gástrica tipo fúndica com moderado grau de hiperplasia do epitélio luminal e foveolar e seriografia com hipertrofia do pregueado mucoso gástrico) confirmaram a doença de Ménétrier.

Palavras-chave: criança; gastrite hipertrófica; ascite; edema; hipoproteinemia.

\section{ABSTRACT}

Objective: To report a case of Ménétrier's disease in a girl.

Case description: A 10-year-old girl was admitted to the hospital with a 3-day history of vomiting, diarrhea, intermittent distension and abdominal pain. Appendicitis was suspected, and patient had a laparotomy which showed only ascites and mesenteric adenomegaly. Generalized edema, ascites and right pleural effusion evolved after the surgery. Menetrier's disease was diagnosed by laboratorial exams and clinical evolution.

Comments: Clinical aspects and the increased fecal alpha1 -antitrypsin associated to gastric mucosa of fundic type with moderate level of hyperplasia of lumina and foveola epithelium and serioscopy with hypertrophy of the plica of gastric mucosa confirmed Ménétrier's disease.

Key-words: child; gastritis, hypertrophic; ascites; edema; hypoproteinemia.
${ }^{1}$ Médica residente da Faculdade de Medicina de São José do Rio Preto (Famerp)

${ }^{2}$ Doutoranda da Faculdade de Medicina da Pontifícia Universidade Católica de São Paulo (PUC-SP)

${ }^{3}$ Médico do Hospital Cândido Rondon de Ji-Paraná em Rondônia

${ }^{4}$ Professor Adjunto do Departamento de Pediatria e Cirurgia Pediátrica da Famerp
Endereço para correspondência:

Antonio Augusto C. Santos

Rua Alexandre Rosa, 145

CEP 15090-100 - São José do Rio Preto/SP

E-mail: antonio.cais@terra.com.br

Recebido em: 27/3/2007

Aprovado em: 30/7/2007 


\section{Introdução}

A doença de Ménétrier ou gastroenteropatia hipertrófica foi descrita em 1888 e caracteriza-se pela hipertrofia das pregas do fundo e corpo gástrico, além da hipersecreção da mucosa com conseqüente gastroenteropatia perdedora de proteína ${ }^{(1)}$. Mais comum em adultos, é muito rara em crianças, com menos de 50 casos descritos, dos quais a maior parte é do gênero masculino. Nas crianças, seu início é súbito, com duração média de cinco semanas e recuperação por vezes espontânea, o que favorece a raridade diagnóstica ${ }^{(2,3-6)}$. A etiologia é desconhecida, mas, em alguns casos, parece relacionada à reação alérgica à proteína alimentar ${ }^{(7)}$ ou à infecção por citomegalovírus ${ }^{(1,8,9)}$, havendo também relatos de casos associados à infecção por Helicobacter pylori ${ }^{(10)}$, Mycoplasma pneumoniae ${ }^{(11)}$ e um caso descrito após a vacinação oral contra poliomielite $\mathrm{e}^{(12)}$.

A análise dos sintomas de 42 casos descritos na literatura mostra a presença de edema hipoproteinemico devido à perda protéica pelo sistema digestório (88\% dos casos), vômitos (78\%), dor abdominal (45\%), anorexia (40\%), sangramento digestivo alto (12\%), além de ascite ${ }^{(13)}$. Em adultos, às vezes, há necessidade de ressecção parcial ou total do estômago ${ }^{(14)}$, como forma de tratamento, e em crianças é, em geral, benigna, com cura espontânea ou após uso de ranitidina ${ }^{(15)}$.

\section{Relato do caso}

Menina de dez anos de idade, branca, natural e procedente de Ji-Paraná, Rondônia, cujos antecedentes pessoais e familiares não revelavam nada digno de nota. Há 50 dias, a paciente apresentou vômitos seguidos de diarréia, com duração de três dias, acompanhados de distensão e dor abdominal. Foi medicada com analgésico/antitérmico, sem melhora. Suspeitou-se de apendicite, sendo submetida, em sua cidade, à laparotomia com achado de ascite e adenomegalia mesentérica, sem confirmação do diagnóstico prévio de apendicite. Evoluiu com edema generalizado e ascite, além de pequeno derrame pleural à direita, no qual foi feita a pesquisa de bacilos álcool-ácido resistentes, com resultado negativo. $\mathrm{O}$ exame sérico para proteínas totais e frações evidenciou acentuada hipoproteinemia. A paciente persistiu com edema e dor abdominal e foi submetida, ainda no serviço de origem, a uma endoscopia digestiva alta que revelou gastrite leve. A biópsia mostrou moderada pangastrite endoscópica erosiva plana, com teste da urease negati- vo e mucosa gástrica tipo fúndica, com grau moderado de hiperplasia do epitélio luminal e foveolar. A lâmina própria evidenciava um discreto infiltrado linfomononuclear e raros plasmócitos, sem sinais de malignidade, compatível com gastrite superficial leve em mucosa de tipo fúndico, com moderada hiperplasia foveolar. Como a doença de Ménétrier às vezes não apresenta características específicas na biópsia, o diagnóstico só poderia ser confirmado pelas características clínica, além dos achados endoscópicos. A ultra-sonografia abdominal evidenciou quantidade moderada de líquido livre na cavidade e, no estômago, aumento da espessura da mucosa, além de edema de alças do delgado. O ecocardiograma mostrou-se normal.

Atendida no serviço universitário em São Paulo, estava em regular estado geral, descorada e referindo dor abdominal. Foram realizados os seguintes exames complementares: hemograma com anemia moderada $(\mathrm{Hb} 9,8 \mathrm{~g} / \mathrm{dL})$ e demais itens sem alterações; glicemia e sódio séricos normais; potássio sérico de $3 \mathrm{mEq} / \mathrm{L}$; creatinina, colesterol total e uréia normais; proteínas totais e frações com hipoproteinemia e hipoalbuminemia de 2,1 g/dL; desidrogenase lática normal; proteína $\mathrm{C}$ reativa normal; teste de d-xilosemia normal; transaminases, bilirrubinas, fosfatase alcalina e amilase normais; sorologia para citomegalovírus IgG e IgM negativas; sorologia para hepatite $\mathrm{A}, \mathrm{B}$ e $\mathrm{C}$ negativas, antiDNA não reagente; fator antinúcleo não reagente; níveis de complemento $\mathrm{C}_{3}$ e $\mathrm{C}_{4}$ normais; Coombs indireto não reagente; velocidade de hemossedimentação aumentada; proteinúria de 24 horas negativa; urina tipo 1 normal; pesquisa de gordura fecal negativa; alfa-1-antitripsina fecal aumentada. A seriografia evidenciou hipertrofia do pregueado mucoso gástrico.

Por se tratar de paciente com edema generalizado e ascite de longa evolução, com características etiológicas relacionadas à hipoproteinemia, focou-se o sistema digestório como causa. Avaliando-se os resultados, concluiu-se tratar da doença de Ménétrier (alfa-1-antitripsina fecal aumentada, mucosa gástrica tipo fúndica com grau moderado de hiperplasia do epitélio luminal e foveolar, e a seriografia com hipertrofia do pregueado mucoso gástrico) ${ }^{(14)}$. Devido à presença de dor abdominal, introduziu-se ranitidina na dose de $150 \mathrm{mg} / \mathrm{dose}$, via oral a cada 12 horas $^{(15)}$, havendo melhora clínica após três dias. Depois de dez dias, a criança encontrava-se em franca recuperação ponderal devido à melhora do apetite, sem dor abdominal, com normalização do nível sérico de potássio e as proteínas totais e frações alcançaram seu nível inferior de referência. 


\section{Comentários}

Ao contrário do adulto, a doença de Ménétrier, na criança, tem evolução com remissão espontânea ${ }^{(14)}$, o que pode explicar o fato de ser pouco diagnosticada. Quanto à melhora clínica com o uso da ranitidina, não existe base suficiente para estabelecer relação direta entre ambos.

\section{Referências bibliográficas}

1. Larsen B, Tarp U, Kristensen E. Familial giant hypertrophic gastritis (Ménétrier's disease). Gut 1987;28:1517-21.

2. Burns B, Gray BB Jr. Ménétrier's disease of the stomach in children. Am J Roentgenol Radium Ther Nucl Med 1968;103:300-6.

3. Degnan TJ. Idiopathic hypoproteinemia. J Pediatr 1957;51:448-52.

4. Bar-Ziv J, Barki Y, Weizman Z, Urkin J. Transient protein losing gastropathy (Ménétrier's disease) in childhood. Pediatr Radiol 1988;18:82-4.

5. Kraut J, Powell R, Hruby M, Lloyd-Still JD. Ménétrier's disease in childhood: report of two cases a review of the literature. J Pediatr Surg 1981;16:707-11.

6. Kadlec G, Goodwin R, Fellows R, Andrews B. Ménétrier's disease in children. South Med J 1979;72:33-6.

7. Fishbein M, Kirschner BS, Gonzales-Vallina R, Ben-Ami T, Lee PC, Weisenberg $\mathrm{E}$ et al. Ménétrier's disease associated with formula protein allergy and small intestinal injury in an infant. Gastroenterology 1992;103:1664-8.

8. Coad NA, Shah KJ. Ménétrier's disease in childhood associated with cytomegalovirus infection: a case report and review of the literature. $\mathrm{Br} \mathrm{J}$ Radiol 1986;59:615-20.

9. Baberán AC, Hubrecht AS, Abás AH, Roig JR, Gratacós JM, Navarro JA. Enfermedad de Ménétrier infantil e infecion aguda por cytomegalovirus. An Pediatr (Barc) 2006;64:478-80
No que se refere à etiologia, também não foi possível determiná-la.

Esse caso, ocorrido em paciente do gênero feminino, é mais um dos poucos relatos de doença de Ménétrier, a qual deve fazer parte das hipóteses diagnósticas diante de edema generalizado e ascite de causa hipoproteinêmica, por perda pelo sistema digestório (enteropatias perdedoras de proteínas) ${ }^{(16)}$.
10. Tokuhara D, Okano Y, Asou K, Tamamori A, Yamano T. Cytomegalovirus and Helicobacter pylori co-infection in a child with Ménétrier disease. Eur J Pediatr 2007;166:63-5.

11. Ben Amitai D, Zahavi I, Dinari G, Garty BZ. Transient protein-losing hypertrophic gastropathy associated with Mycoplasma pneumoniae infection in childhood. J Pediatr Gastroenterol Nutr 1992;14:237-9.

12. Kawakami E, da Cruz AS, Patrício FR, Medeiros EH, Wehba J, Fagundes Neto U. Doença de Ménétrier na criança: relato de três casos e revisão da literatura. Arq Gastroenterol São Paulo 1990;27:33-40.

13. Sferra TJ, Buk LI, Qualman SJ. Ménétrier's disease in children: a cytomegalovirus induced gastropathy? Gastroenterology 1990;98:A122.

14. Scharschimidt BF. The natural history of hypertrophic gastropathy (Ménétrier disease): report of a case with 16 years follow up and review of 120 cases from the literature. AM J Med 1977;63:644-52.

15. Kang JY, Tang KF, Goh A, Sundran FX, Seah CS. Remission of Ménétrier's disease associated with ranitidine administration. Aust N Z J Med 1990; 20:716-7

16. Motta ME, Silva GA. Gastroenteropatia perdedora de proteínas. In: Ferreira CT, Carvalho E, Silva LR, editores. Gastroenterologia e hepatologia em pediatria: diagnóstico e tratamento. Rio de Janeiro: Medsi; 2003. p. 179-80.

\section{Errata}

As Figuras 1 e 2 do artigo "Lupus eritematoso discóide na infância", publicado em junho de 2007, não correspondem à lesão aguda do lúpus eritematoso como está indicado na $11^{a}$ linha do segundo parágrafo da Revisão da literatura, na página 168, e sim

a lesões discóides." 